\title{
Theoretical aspects of the study of parental resilience, raising children with disabilities
}

\author{
Elena Tkach ${ }^{1, *}$, Elisa Nazareth Mendoza Ortega ${ }^{1}$ \\ ${ }^{1}$ Pacific National University, Russia
}

\begin{abstract}
The presence of a child with disabilities is a powerful stressor for his parents, leading to a serious adjustment disorder. Based on a theoretical analysis of the main approaches to the phenomenon of psychological personality resilience, the resilience of parents raising children with disabilities is considered as a subject resource that provides positive adaptation and full-fledged life activity in spite of adverse living conditions. Resilience is characterized by a combination of social and intrapsychic processes that allow a person to be healthy and live a full life in an unfavorable environment. The ability of parents raising children with disabilities to cope with an adverse life situation is influenced by many factors: state policy in relation to this category of people, the media, public moods, school, social institutions, and interactions with people, family dynamics and resilience resources, stress factors, socio-economic characteristics of the family. The main characteristics of the resilience of parents raising children with disabilities are: the possibility of selfexpression, general involvement, openness, awareness, a harmonious relationship between caring for the child and the need for attention of other family members. Despite difficult life circumstances, parents raising children with disabilities can find resources to adapt positively to the stress they experience. There are recommendations for certain actions, psychological intervention programs for the development of resilience in such families. In psychological practice, in a situation where a family has a child with disabilities, all attention and care is given to him.
\end{abstract}

\section{Introduction}

The study of resilience occupies a special place in modern psychological science [1-15]. From the first studies in the 1970 s to the present, a large amount of empirical data and numerous theoretical developments and practical techniques for the study of resilience has been accumulated. The importance and relevance of research on resilience is growing in the face of significant socio-economic changes, the emergence of new global risks, anthropological crises and disasters, changing living conditions and social institutions. The use of knowledge obtained in the study of resilience can contribute to the development of a person who is able to adapt positively despite adverse conditions and dangerous circumstances.

\footnotetext{
* Corresponding author: elenat3004@mail.ru
} 
In recent years, there has been a significant increase in the number of children with disabilities. The UN World Health Organization confirms the fact that every twentieth child under the age of 14 has a moderate or severe degree of developmental disability.

There is a large amount of information in the scientific literature on the interdisciplinary rehabilitation of children with disabilities in order to achieve their maximum potential for improving the quality of life and the maximum possible functionality; however, it is obvious that information on assistance to parents and family members with children with disabilities is disproportionately smaller. It should also be emphasized that in Russia the problem field of research on resilience is a rather young direction, and special studies of the resilience of parents raising children with disabilities are extremely rare.

Parents raising children with disabilities are exposed to all sorts of difficulties, ranging from financial troubles to social problems. Having a child with a disability in the family puts it into a position of extreme vulnerability and threatens healthy family dynamics. Resilience research in families raising children with disabilities is gaining vital importance and relevance. If professional psychologists know more about resilience, they will be able to help and orient parents in difficult life situations in the direction of improving the quality of their own life and the life of their child.

\section{Main part}

The presence of a child with disabilities in the family in the scientific literature is estimated as an extremely strong stressor, or, in other words, a stress factor, a threat, a challenge or excessive requirements that exceed the adaptive abilities of a particular person and the whole family.

The category of children with disabilities includes children under 18 years of age with significant disabilities, leading to social misadaption due to impaired development and growth of the child, self-care, movement, orientation, control over their behavior, education, communication, future work.

In the modern scientific space, various concepts are used that describe the phenomenology of developmental restrictions, for example, such as: dysontogenesis, developmental anomaly, health limitations, disability, and others.

The category of people with developmental disabilities should include people of different ages, sexes, social status, who have difficulty or impairment, in varying degrees of severity, which can be physical or psychomotor, mental, cognitive or sensory.

In modern defectology the term 'developmental anomaly' is adopted as applied to dysontogenesis.

Early developmental disorders of the central nervous system can be caused by both biological and social factors.

The biological factors of dysontogenesis include:

- genetic (hereditary metabolic diseases, chromosomal aberrations, gene mutations, endogenous diseases, etc.);

- prenatal disorders (toxicosis of pregnancy, conflicts in the blood system, in particular, Rh conflict, intrauterine infections, intoxications, etc.);

- pathology of childbirth;

- early diseases with a primary lesion of the central nervous system (metabolic defects, progressive hydrocephalus, degenerative diseases, brain tumors, encephalitis, schizophrenia, etc.).

The social factors of dysontogenesis include:

- various types of emotional and social deprivation;

- various kinds of social psychological stresses. 
Modern researchers identify such types of mental dysontogenesis in children as: underdevelopment, mental retardation and damaged mental development. Their characteristic follows.

The most typical model of mental underdevelopment is the state of oligophrenia. Oligophrenia as a special form of mental underdevelopment manifests itself in a persistent decrease in cognitive activity in children due to organic brain damage in the perinatal and early postnatal periods. The main forms of oligophrenia are:

- uncomplicated form of oligophrenia,

- oligophrenia complicated by impaired neurodynamics,

- oligophrenia with a disorder of various analyzers,

- oligophrenia with psychopathic forms of behavior,

- oligophrenia with severe frontal insufficiency.

Mental retardation is much more common than oligophrenia. In this case, we are not talking about the irreversible underdevelopment of the psyche, but about a slowdown in the pace of its development, expressed in the inadequacy of the general stock of knowledge, limited representations, immaturity of thinking, the predominance of gaming interests over the determined social situation of development, quick satiety in intellectual activity, and emotional immaturity.

Damaged mental development is associated with previous infections, intoxications, injuries of the nervous system, hereditary degenerative, metabolic diseases of the brain and is characterized by a partiality of disorders. For differential diagnosis with oligophrenia, the indication of the initial correct and timely development of the child before the period of the infection, intoxication or brain injury and the chronological relationship of mental decline with the harmfulness are of fundamental importance. In neurological status, local signs (paresis, paralysis, seizures) are more often noted.

UN Children's Fund UNICEF has identified the following patterns of developmental disabilities:

Medical model of developmental disorders.

This model represents the disorder as a disease or medical problem that can be corrected or cured. A person who suffers from a disease is seen as something that has been broken and therefore needs to be repaired. Many people undergo surgical intervention every day, because they themselves are convinced of their abnormality, and also that they will not be able to exist if this is not corrected immediately. This model is based on the following statements:

- disorder is something negative,

- if someone has a disability - this is a huge problem for him,

- the solution to the problem is to cure such a child and as quickly as possible,

- Only a professional specialist can help a child with a developmental disability and integrate him / her into public life.

Charity Development Disruption Model

This model considers people with developmental disabilities as worthless and hopeless, therefore in need of care. It is extremely difficult for many people to overcome fear, anxiety, the inconvenience of interacting with people with disabilities, so they show charity and sympathy. In reality, people with developmental disabilities have the same rights and obligations as everyone else, and therefore they should not be treated differently, especially with pity.

Social model of developmental disabilities

This model focuses on the abolition, destruction, erasure of any barriers erected by society in order to impede the development and observance of the rights of persons with disabilities. In particular, it considers changes in public relations, changes in the external environment in such a way that anyone can freely receive adequate and necessary information about people with disabilities and disabilities, and also be involved in the process of removing barriers: 
- disease, disability is simply a difference of the same kind as gender or race;

- diseases cannot be considered in terms of "good" or "bad", this is a property of a disabled person,

- a person with developmental disabilities in a closed external environment will not be able to use his legal rights,

- for a full-fledged, adequate process of including people with developmental disabilities in social life, it is necessary to change social norms, the way of thinking of "normal" people, and change the infrastructure.

The main approach used in this work is based on the fact that the necessary level of care, assistance to a child with disabilities, required from his parents and other family members is a stressor, defined as a threat, a challenge, a specific request that exceeds the capabilities of an individual person to adapt. Parents of children with intellectual disabilities, as a rule, report a higher level of stress, anxiety, and depression, since the very presence of such a child in the family is a factor that can seriously alter the family system and family dynamics. From the moment parents first learn about the problems of their child, they begin to change their patterns of behavior and habits and go through a rather complicated process of raising their child with a high level of stress.

Of course, the parents of children with developmental disabilities are forced to devote much more time and many times more efforts to them than parents raising «ordinary» (neurotypical) children «within normal». It is important to take into account all the factors that influence parents raising children with disabilities, as these factors can be sources of stress and troubles that significantly reduce the quality of life.

One cannot disagree with the Czech researcher Iva Strnadova [16], who identifies the following groups of factors affecting parents raising such children and the family's ability to cope with this problem. The levels (groups) of these factors are presented below.

The first level refers to the impact on the family of public policies regarding children with disabilities. In addition, media coverage reflecting state policy and public sentiment is also attributed to the same level.

The second level shows the institutional effect, including schools, the possibility and availability of special workers, specialists in working with such children, as well as public attitudes towards people with developmental disabilities.

At the third level, all aspects of the second level are presented in detail. For example, how a school affects parents: the authority of the school, the level of school education, the quality of the interaction between family and school.

At the fourth level are factors regarding the ability of parents to cope, adapt to the disorder of the child and the ability to contribute to the correction or alleviation of suffering. Family dynamics and family resilience are part of these factors.

The fifth level means the possible existence of other stressful factors that, in the final effect, influence how parents perceive the lack of their child.

As a result of many years of research, many scientists have come to the general conclusion that the pathology that makes it impossible for the child to adapt is the key basis for the deep stress of the parents of children with disabilities, who also experience additional stress due to the need to provide special care for the child and the burden of serious financial problems.

At the same time, some recent studies have shown that, although some families do carry a high risk due to multiple difficulties, any family is able to find reserves in order to adapt positively to this stress.

Currently, in the scientific literature there are many definitions of the concept of «adaptation», which are interpreted ambiguously. The phenomenon of adaptation is an object of interdisciplinary research, since it can be applied to various aspects of adaptation: biological, psychological, social. Adaptation is usually determined in the framework of social 
viability, manifested through human behavior or a successful response to challenges at the appropriate stage of development.

When performing a research of resilience, one of the main tasks is to determine the emotional characteristics of parents raising children with disabilities who are related to the concept of resilience, and to find out the presence or absence of a relationship between the nature of the child's disturbance and the effect on the mechanism of family adaptation.

Grotberg E. proposed a three-factor model of resilience («I have», «I - ...», «I can»), presented below.

In accordance with the ideas of Grotberg E., the criteria and characteristics of a resilient family include the following.

- A resilient family is able to express anger, guilt, sadness, but without a transition to direct actions. That is, at some point in time, a family member may express their internal discomfort and fatigue associated with the need to care for the child, but this should not lead to the abandonment of care for a child with disabilities. Rather, it is a way of expressing the limitations of one's own efforts and the need to ask for help from other family members.

- In a resilient family, everyone is involved, depending on their abilities, in caring for a problem child. The responsibility for caring for a disabled child should not lie entirely with the mother.

- A resilient family is constantly looking for a solution to the child's disability problem. Members offer such solutions, but they are also in a position to adopt harsh and cruel reality when, for medical reasons, they are informed that there is no possibility of improvement or cure of the child.

- A resilient family is able to detect the "positive side" of a child's disability (strengthening family cohesion, opening the ability to involve family members, understanding the values of solidarity and respect for others, etc.) and, on this basis, build a more complete, happier life.

- A resilient family does not hide in suffering, but, as far as possible, is open to other relationships and help from relatives and friends.

- The resilient family is well informed about the nature of the child's disability, constantly monitors information about possible treatment methods, the state of medical research that can help the child recover.

- A resilient family will strive for a cordial, disposing relationship and, at the same time, to resolve possible conflicts and tensions with the disabled person. This will be achieved if a disabled child feels loved, accepted and understood by other family members.

- A resilient family can harmonize the attention given to a child with a disability with the attention needs of other family members. Resilient family provides care for the child, without giving up their own relationships and family dynamics.

The development of resilience, the ability to positively cope with the life difficulties of a person should be supported by the family and the environment from childhood through affective manifestations, both physical and verbal.

Table 1. Three-factor Resilience Concept (Grotberg).

\begin{tabular}{|c|c|c|c|}
\hline \multicolumn{1}{|c|}{ I have } & \multicolumn{1}{|c|}{ I - } & \multicolumn{1}{c|}{ I can } \\
\hline 1 & $\begin{array}{l}\text { people next to me whom I } \\
\text { trust who will love me no } \\
\text { matter what }\end{array}$ & $\begin{array}{l}\text { am a person who can be } \\
\text { liked and loved by others }\end{array}$ & $\begin{array}{l}\text { talk to someone about } \\
\text { what bothers or scares me }\end{array}$ \\
\hline
\end{tabular}




\begin{tabular}{|c|l|l|l|}
\hline 2 & $\begin{array}{l}\text { people who will explain to } \\
\text { me the limits so that I will } \\
\text { know when to stop, so as } \\
\text { not to get into trouble or a } \\
\text { dangerous situation }\end{array}$ & $\begin{array}{l}\text { am happy to do something } \\
\text { useful for others and show } \\
\text { my concern for them }\end{array}$ & $\begin{array}{l}\text { find a solution to the } \\
\text { problems that are } \\
\text { encountered in my way }\end{array}$ \\
\hline 3 & $\begin{array}{l}\text { people who will show me } \\
\text { how to do things right by } \\
\text { example }\end{array}$ & $\begin{array}{l}\text { people who want me to } \\
\text { learn from my own } \\
\text { experience }\end{array}$ & strive for responsibility for \\
what I do & $\begin{array}{l}\text { understand when you need } \\
\text { to talk with someone or } \\
\text { urgently take action }\end{array}$ \\
\hline 5 & $\begin{array}{l}\text { people who will help me } \\
\text { when I feel bad, when I } \\
\text { am in danger, or when I } \\
\text { need to learn something } \\
\text { that I am in danger or do } \\
\text { wrong }\end{array}$ \\
\hline
\end{tabular}

Resilient parents can by their activity contribute to enhancing the development of the resilience of their children. To enhance the manifestation of resilience, parents can adhere to the following recommendations:

- Encourage tasks with minimal adult involvement;

- participate in the development of speech;

- help in expressing feelings and emotions;

- support in stressful situations;

- To develop a sense of independence and conviction that problems need and can be solved;

- to offer in conflict situations at school to be ready for dialogue,

- support the expression of empathy;

- welcome the successes and positive patterns of behavior of the child, respectful and polite behavior, adequate expression of feelings and emotions;

- promote understanding of the acceptance of duties and responsibilities for the consequences of their actions.

Adults should provide the necessary assistance to children, while avoiding excessive rigidity and maintaining a balance between help and independence, developing opportunities for the child to express feelings and emotions through words and constructively perceive the mistakes made so that the child feels and understands that he made a mistake, but despite this is not lost parental support.

The following parental actions contribute to the development of resilience in children:

- emotional expression in both physical and verbal form,

- following the rules,

- maintaining an appropriate attitude that expresses confidence, optimism so that children can perceive it as a role model,

- celebrating and celebrating the successes and achievements of children,

- motivation of children to perform new activities,

- encouraging an understanding of the nature of one's and others 'emotions,

- gradual preparation of the child to face unpleasant or difficult situations,

- patience as the understanding that a child needs some time in order to change and make new acquired qualities a part of his life. 
Since resilience can be considered as a personal, social or cultural strategy for survival and overcoming adverse life circumstances, the role of a professional psychologist seems quite important both for himself and for those to whom he is trying to assist in the development of resilience. The role of a professional must meet the following conditions:

- determine internal resources, family capabilities, in order to subsequently disclose them to parents or other family members, relatives, because, usually, these people do not realize the availability of such resources. After the work of a psychologist, they can be strengthened and used. This can contribute to the departure of family members from a negative outlook on circumstances, to a more positive one, which makes it possible to detect qualities and dignities that allow them to cope with difficult life circumstances, and this differs from other people;

- focus not on the problems that the family or the individual is exposed to, but rather determine the qualities and dignity of the family and the individual;

- Do not focus your eyes on the somatic or mental symptoms of the individual, but consider him as a person, as a whole, body and intellect, defects and virtues, limitations and achievements;

- take into account the external environment, as in many cases it is a source of support and help that overcomes the loneliness in which the family is located;

- situate problems in an appropriate context, whether it is economic, social or political, so that the individual, family will gain a better understanding of existing opportunities;

- replace pessimistic forecasts and negative conclusions with the hope of improvement;

- develop and try development strategies together with the family;

- follow ethical requirements - treat clients with warmth, refuse to condemn, show understanding, empathy;

- possess sufficient ability to empathy for the understanding of their customers;

- the ability to be a good listener, both in order to have a good psychotherapeutic relationship, and to show interest in clients;

- establish friendly relations, which implies a respectful relationship between professional and clients;

- Set the mood for hope and faith in the ability of the family.

In general, the ability of parents raising children with disabilities to cope with an adverse life situation is affected by many factors at many levels.

Among the main characteristics of the resilience of parents raising children with disabilities are the following:

- the possibility of self-expression,

- general involvement in caring for a problem child, finding a solution to a child's problem;

- openness;

- awareness;

- A harmonious relationship between caring for a child and the need for attention of other family members.

There are recommendations for certain actions, intervention programs for the development of resilience in such families. Thus, the development of resilience is facilitated by the manifestation of affection, the establishment and maintenance of clear rules, the maintenance of optimism, common family ceremonies (joint celebration of celebrations and the celebration of any new successes), motivation for new activities, etc.

Studies by many scientists show that, despite difficult life circumstances, any family can find resources in order to adapt positively to stress. 


\section{Conclusions}

The phenomenon of resilience, studied since the 70s of the last century, is of considerable theoretical and practical interest. As a result of this work, the following aspects of the problem were identified:

1. On the basis of a theoretical analysis of the main approaches to the phenomenon of psychological resilience for the purposes of this work, the concept of resilience is used as a positive adaptation in spite of adverse conditions and / or dangerous circumstances. At the same time, resilience is characterized by a combination of social and intrapsychic processes that allow a person to be healthy and live a full life in an unfavorable environment.

2. The presence of a child with disabilities represents a powerful stressor for his parents, leading to a serious adjustment disorder.

3. The ability of families, parents raising children with disabilities to cope with adverse life situations is influenced by many factors at many levels, including: state policy regarding this category of people, the media, public moods, school, social institutions, interactions with the environment, family dynamics and resources of resilience, stress factors, socio-economic characteristics of the family.

4. Based on available research, the main characteristics of the resilience of parents raising children with disabilities are highlighted. Among them are the possibility of self-expression, general inclusion; openness awareness; a harmonious relationship between caring for a child and the need for attention of other family members.

5. Despite difficult life circumstances, parents raising children with disabilities can find resources to adapt positively to the stress they experience. There are recommendations for certain actions, psychological intervention programs for the development of resilience in such families.

6. In psychological practice, in a situation where a family has a child with disabilities, all attention and care are paid to him. Unfortunately, parents who support the child are often not taken into account, they simply forget about them. At the same time, providing them with psychological assistance aimed at developing their resilience could make their life much better, and at the same time improve the lives of their child suffering from disabilities.

\section{References}

1. L.G. Dikaya, A.V. Makhnach, A.I. Laktionova, Social and Humanitarian Sciences in the Far East 15(4), 137-146 (2018) DOI: 10.31079/1992-2868-2018-15-4-137-146

2. S.N. Vasilyeva, E.A. Rylskaya, Yaroslavl Pedagogical Bulletin 2(107), 106-113 (2019) DOI: $10.24411 / 1813-145 X-2019-10358$

3. A.V. Makhnach, Vestnik RGGU (Bulletin of the Russian State Humanitarian University). Series: Psychology. Pedagogy. Education 2, 37-50 (2019) DOI: $10.28995 / 2073-6398-2019-2-37-50$

4. A.V. Makhnach, A.I. Laktionova, Yu.V. Postylyakova, Social and Humanitarian Sciences in the Far East 15(4), 45-54 (2018) DOI: 10.31079/1992-2868-2018-15-4-4554

5. A.V. Makhnach, Bulletin of the Kostroma State University. Series: pedagogy. Psychology. Sociokinetics 25(2), 46-51 (2019) DOI: 10.34216/2073-1426-2019-25-246-51

6. A.V. Makhnach, Journal of Psychology 38(4), 5-16 (2017) DOI: $10.7868 / \mathrm{S} 0205959217040018$ 
7. B. Daniel, S. Vincent, E. Farrall, F. Arney, International Journal of Child \& Family Welfare 1, 2-21 https://www.researchgate.net/publication/228500464_How_is_the_Concept_of_Resilie nce_Operationalised_in_Practice_with_Vulnerable_Children

8. A.V. Makhnach, International Journal Of Adolescence And Youth 21(2), 195-214 (2016) DOI:10.1080/02673843.2013.815116

9. A.J. Zautra, J.S. Hall, K.E. Murray, Resilience: A new definition of health for people and communities. Handbook of Adult Resilience (New York, London, Guilford Press, 2010) https://www.researchgate.net/publication/232581337_Resilience_

A_new_definition_of_health_for_people_and_communities

10. D. Fletcher, M. Sarkar, European Psychologist 18, 12-23 (2013) DOI: 10.1027/10169040/a000124

11. O. Hjemdal, O. Friborg, S. Braun, P. Fossion, International Journal of Testing 11, 5370 (2011) https://doi.org/10.1080/15305058.2010.508570

12. T.D. Letzring, J. Block., D.C. Funder, Journal of Research in Personality 39, 395-422 (2005) DOI:10.1016/j.jrp.2004.06.003

13. I. Salisu, N. Hashim, IOSR Journal of Business and Management (IOSR-JBM) 19(4), 23-33 (2017) DOI: 10.9790/487X-1904032333

14. W. Smith, J. Dales, K. Wiggins, K. Wiggins, E. Tooley, P. Christopher, J. Bermard, International Journal of Behavioral Medicine 15, 194-200 (2008) DOI:10.1080/10705500802222972

15. G. Windle, D.A. Markland, R.T. Woods, Aging and Mental Health 12(3), 285-292 (2008) DOI: 10.1080/13607860802120763

16. I. Strnadova, Revista Complutense de Educación 17(2), 35-50 (2006) https://www.researchgate.net/publication/27592918_Stress_and_resilience_in_families _of_children_with_specific_learning_disabilities 